\title{
AFINIDADE METÁLICA E ESTUDO CINÉTICO DA ADSORÇÃO DE ÍONS DE CÁDMIO EM PARTÍCULAS DE SERICINA/ALGINATO
}

\author{
J. O. LIMA $^{1 *}$, M. F. RAGASSI ${ }^{1}$, M. G. A. VIEIRA ${ }^{1}$, M. L. GIMENES ${ }^{2}$, M. G. C. SILVA ${ }^{1}$ \\ ${ }^{1}$ Universidade Estadual de Campinas, Faculdade de Engenharia Química \\ ${ }^{2}$ Universidade Estadual de Maringá, Departamento de Engenharia Química \\ *e-mail: jlima@feq.unicamp.br
}

\begin{abstract}
RESUMO
A adsorção pode ser utilizada como uma técnica eficiente para a remoção de metais tóxicos em águas residuais. Resíduos industriais como a sericina, geralmente descartada em efluentes de processos de fiação, podem atuar como bioadsorventes. $\mathrm{O}$ uso de alginato na formação da blenda com essa proteína visa melhorar as características físicas das partículas produzidas. Experimentos cinéticos em banho finito foram conduzidos e os modelos de pseudoprimeira ordem, pseudossegunda ordem e difusão intrapartícula foram ajustados aos dados experimentais. Os resultados mostraram que quanto maior a concentração inicial de $\mathrm{Cd}^{2+}$, maior a capacidade de adsorção. Além disso, o modelo de pseudossegunda ordem se ajustou mais adequadamente e a partir do ajuste do modelo de difusão intrapartícula, verificou-se que a difusão no interior da partícula não é a única etapa que controla o processo de transferência de massa. A área superficial determinada pelo método BET foi de 3,702 $\mathrm{m}^{2} \cdot \mathrm{g}^{-1}$. Os resultados sugerem que as partículas de sericina/alginato têm boa possibilidade de serem usadas como bioadsorventes eficazes para a remoção de $\mathrm{Cd}^{2+}$.
\end{abstract}

\section{INTRODUÇÃO}

A poluição ambiental decorrente do desenvolvimento tecnológico constitui um problema crítico, principalmente, no que se refere aos metais tóxicos, poluentes potenciais amplamente encontrados em efluentes industriais.

Dentre os metais tóxicos, o cádmio foi classificado como um carcinógeno humano e teratogênico impactando pulmões, rins e o fígado e tem sido liberado para o meio ambiente por meio da queima de combustíveis fósseis, aplicação de fertilizantes fosfatados, galvanoplastia e fabricação de baterias e pigmentos (BOPARAI, JOSEPH e O'CARROLL, 2011).

Os métodos convencionais para a remoção de íons metálicos tóxicos a partir de águas residuais incluem a redução química, osmose reversa, co-precipitação, coagulação, a complexação, tratamento eletroquímico e adsorção (AGRAWAL e SAHU, 2006). A adsorção é considerada bastante atrativa considerando sua eficiência de remoção de poluentes em soluções diluídas (AZOUAOU ET AL., 2010) e, geralmente, envolve o uso de adsorventes convencionais como as resinas sintéticas de troca iônica e os carvões ativados que são eficientes na remoção de vários poluentes. No entanto, são materiais 
normalmente caros e seu custo de regeneração também é elevado, motivando, assim, a busca por novos materiais de baixo custo para serem utilizados como bioadsorventes.

A bioadsorção é baseada na capacidade de ligação dos metais com vários materiais biológicos, que surge como alternativa, principalmente quando são utilizados resíduos de operações industriais, como é o caso da sericina, descartada no processamento da seda.

A sericina, proteína que constitui de 20 a $30 \%$ da massa total de casulos do bicho-daseda, possui aminoácidos com fortes grupos polares tais como hidroxila, carboxila e grupos amino. Estes grupos permitem a reticulação, copolimerização e formação de blendas com outros polímeros, como o alginato, de modo a melhorar suas características, uma vez que a sericina apresenta fracas propriedades estruturais e alta solubilidade em água (ZHANG, 2002).

$\mathrm{O}$ alginato é um polissacarídeo de fácil obtenção, por ser proveniente de fontes naturais, renováveis e abundantes, como em algas marrons e bactérias, e é importante por ser biodegradável e ter boa biocompatibilidade (NITÃ ET AL., 2007).

$\mathrm{O}$ objetivo deste trabalho foi investigar o uso de partículas produzidas de sericina/alginato como bioadsorvente em processos de adsorção de íons metálicos. Ensaios preliminares de afinidade metálica foram realizados para avaliar o potencial de remoção dos íons de $\mathrm{Cu}^{2+}, \mathrm{Zn}^{2+}, \mathrm{Cd}^{2+}, \mathrm{Pb}^{2+}$, $\mathrm{Ni}^{2+}, \mathrm{Cr}^{3+}$ e $\mathrm{Ag}^{1+}$ pelo bioadsorvente em estudo. A partir do resultado de afinidade, fez-se o estudo cinético de remoção de $\mathrm{Cd}^{2+}$ de soluções metálicas, verificando a influência de sua concentração inicial. Os modelos cinéticos de pseudoprimeira ordem, pseudossegunda ordem e difusão intrapartícula foram utilizados para avaliar os mecanismos de adsorção.

\section{MATERIAIS E MÉTODOS}

\subsection{Preparação das Partículas}

Para a obtenção da sericina, utilizaramse casulos do bicho-da-seda da espécie Bombyx Mori $L$. fornecidos pela empresa Fiação de Seda Bratac S/A do Paraná. Os casulos foram limpos, cortados em partes de aproximadamente $1 \mathrm{~cm}^{2}$, lavados e mantidos em estufa a $50{ }^{\circ} \mathrm{C}$ durante 24 horas para que alcançasse massa constante.

Em seguida, procedeu-se a etapa de extração de sericina, em que os casulos secos foram inseridos em Erlenmeyer com água destilada numa proporção de $4 \mathrm{~g}$ de casulos para $100 \mathrm{~mL}$ de água (4:100). O Erlenmeyer vedado foi colocado em uma autoclave (Phoenix Luterco, AV-18, Brasil) na qual permaneceu durante 40 min após alcançar a pressão de $1 \mathrm{kgf} / \mathrm{cm}^{2}\left(\mathrm{~T}=120^{\circ} \mathrm{C}\right)$. Após esse tempo, filtrou-se a quente a solução obtida e transferiu-se o filtrado para outro recipiente, que permaneceu à temperatura ambiente $\left(\mathrm{T}=25^{\circ} \mathrm{C}\right)$ por 24 horas.

A etapa de fracionamento, que consiste em separar a fração de sericina de maior massa molar, compreendeu o acondicionamento em congelador convencional por no mínimo $24 \mathrm{~h}$ da solução obtida na extração. Em seguida, a solução foi mantida em temperatura ambiente para descongelar, ocorrendo uma separação de fases; a solução foi filtrada em papel-filtro.

A concentração da sericina foi determinada pelo método das massas e então ajustada para $25 \mathrm{~g} / \mathrm{L}(2,5 \% \mathrm{~m} / \mathrm{v})$. Para a obtenção da blenda, foi incorporado o alginato de sódio comercial (Sigma-Aldrich, Reino Unido) numa proporção de $2 \%(\mathrm{~m} / \mathrm{v})$ na solução ajustada de sericina, sob agitação constante.

As partículas foram preparadas a partir da incorporação de cálcio na blenda por meio 
de seu gotejamento em uma solução aquosa $3 \%(\mathrm{~m} / \mathrm{v})$ de cloreto de cálcio $\left(\mathrm{CaCl}_{2}\right)$, também sob constante agitação. Para isso, utilizou-se uma bomba peristáltica (Masterflex L/S, 77800-60, EUA) à vazão constante.

Ao final deste processo, as partículas formadas foram mantidas em agitação constante na solução de cloreto de cálcio durante 12 horas para finalizar o processo de reticulação. Posteriormente, as partículas foram secas à temperatura ambiente, e então mantidas em um forno de fluxo contínuo a $100{ }^{\circ} \mathrm{C}$ por 24 horas para que ocorresse a reticulação térmica, a fim de melhorar as propriedades mecânicas das partículas.

Após a preparação foi realizada a análise de área superficial da partícula da blenda sericina/alginato. A medida da área superficial específica das partículas foi obtida pelo método de Fisissorção de $\mathrm{N}_{2}$ (Método BET) utilizando o equipamento NOVA1200e (Quantachrome, Alemanha). A amostra foi tratada termicamente a vácuo antes da análise a $90{ }^{\circ} \mathrm{C}$ para garantir a inexistência de água ou outro material condensado em seus poros. Esta análise também foi efetuada com a blenda após o processo de adsorção.

\subsection{Teste de Afinidade Metálica}

Os ensaios foram realizados para definir qual o íon metálico o material possui maior afinidade de adsorção e, assim, definir o metal para realização dos ensaios de cinética deste trabalho. Esses testes foram realizados com os seguintes íons metálicos: $\mathrm{Cu}^{2+}, \mathrm{Zn}^{2+}, \mathrm{Cd}^{2+}$, $\mathrm{Pb}^{2+}, \quad \mathrm{Ni}^{2+}, \quad \mathrm{Cr}^{3+}$ e $\mathrm{Ag}^{1+}$, em solução monocomposto.

Na primeira etapa foi feita a especiação química dos sais metálicos visando identificar as diferentes espécies presentes em soluções aquosas para determinados valores de $\mathrm{pH}$. Os diagramas de especiação metálica em função do $\mathrm{pH}$ foram simulados usando o programa
Hydra (PUIGDOMENECH, 2004). De acordo com os diagramas, o $\mathrm{pH}$ teve que ser mantido abaixo do ponto de mínima precipitação para evitar a formação de complexos durante o experimento. $\mathrm{O}$ ajuste do $\mathrm{pH}$, quando necessário, foi realizado com solução diluída de ácido nítrico.

Os sais metálicos utilizados no preparo das soluções sintéticas foram o nitrato de cobre trihidratado $\left[\mathrm{Cu}\left(\mathrm{NO}_{3}\right)_{2} .3 \mathrm{H}_{2} \mathrm{O}\right]$, nitrato de zinco hexahidratado $\left[\mathrm{Zn}\left(\mathrm{NO}_{3}\right)_{2} \cdot 6 \mathrm{H}_{2} \mathrm{O}\right]$, nitrato de cádmio tetrahidratado $\left[\mathrm{Cd}\left(\mathrm{NO}_{3}\right)_{2} .4 \mathrm{H}_{2} \mathrm{O}\right]$, nitrato de chumbo $\left[\mathrm{Pb}\left(\mathrm{NO}_{3}\right)_{2}\right]$, nitrato de níquel hexahidratado $\left[\mathrm{Ni}\left(\mathrm{NO}_{3}\right)_{2} .6 \mathrm{H}_{2} \mathrm{O}\right]$, nitrato de cromo nonahidratado $\left[\mathrm{Cr}\left(\mathrm{NO}_{3}\right)_{3} .9 \mathrm{H}_{2} \mathrm{O}\right]$ e nitrato de prata $\left(\mathrm{AgNO}_{3}\right)$, todos da Vetec (Brasil).

Para tanto, foi inserido $1 \mathrm{~g}$ de partícula da blenda sericina/alginato em cada Erlenmeyer, o qual comportava $100 \mathrm{~mL}$ de uma determinada solução metálica com concentração de $1 \mathrm{mmol} / \mathrm{L}$, ou seja, solução monocomposto dos citados íons metálicos. Logo após, colocaram-se os Erlenmeyers em um Shaker (Jeio Tech, SI-600R, Coréia) sob agitação constante de $250 \mathrm{rpm}$ e temperatura de $25^{\circ} \mathrm{C}$ durante $24 \mathrm{~h}$, tempo necessário para atingir o equilíbrio.

Em seguida, a fase fluida de cada amostra foi centrifugada e o sobrenadante diluído para análise de concentração dos metais por espectrofotometria, utilizando o Espectrofotômetro de Absorção Atômica (Shimadzu, AA-7000, Japão). A determinação da concentração dos metais na solução foi realizada antes e após o processo de adsorção para obter a capacidade de adsorção (q) e porcentagem de remoção (\%R) do metal analisado, calculadas pelas Equações 1 e 2, respectivamente.

$q=\frac{\left(C_{0}-C\right) \cdot V}{m_{p}}$ 
$\% R=\frac{\left(C_{0}-C_{e}\right)}{C_{0}} .100$

sendo: $C_{0}=$ concentração do íon metálico na solução inicial $(\mathrm{mmol} / \mathrm{L}) ; \mathrm{C}=$ concentração do íon metálico na solução final $(\mathrm{mmol} / \mathrm{L})$; $C e=$ concentração do íon metálico no equilíbrio $(\mathrm{mmol} / \mathrm{L}) \mathrm{V}=$ volume da solução metálica $(\mathrm{L}) ; m_{p}=$ massa da partícula $(\mathrm{g})$; $\mathrm{q}=$ capacidade de adsorção $(\mathrm{mmol} / \mathrm{g})$.

\subsection{Ensaios Cinéticos}

Os experimentos de adsorção foram realizados em banho finito, à temperatura ambiente $\left(25^{\circ} \mathrm{C}\right)$ com a adição de $4 \mathrm{~g}$ de partículas em $500 \mathrm{~mL}$ de soluções de cádmio com concentrações iniciais de 0,$5 ; 1$ e 1,5 $\mathrm{mmol} / \mathrm{L}$. O sistema (solução e partículas) foi mantido sob agitação constante e, em intervalos de tempos pré-determinados, foram retiradas alíquotas de $1,5 \mathrm{~mL}$ da solução, as quais foram centrifugadas e diluídas para análise por espectrofotometria.

A capacidade de adsorção foi calculada pela Equação 1.

\subsection{Modelos Cinéticos}

Para determinar os mecanismos da adsorção de $\mathrm{Cd}^{2+}$ por partículas de sericina/alginato, foram avaliados os seguintes modelos cinéticos:

\subsubsection{Modelo de Pseudoprimeira Ordem}

Modelo cinético representado pela equação de Lagergren que descreve a adsorção em sistemas sólido-líquido baseada na capacidade de adsorção dos sólidos (Ho, 2004). Assume-se que um íon metálico é adsorvido em um sítio de adsorção na superfície do adsorvente e é expresso pela Equação 3:

$q=q_{e}\left(1-e^{-K_{1} t}\right)$ em que: $q_{e}$ é a capacidade de adsorção no equilíbrio $\left(\mathrm{mmol} . \mathrm{g}^{-1}\right) ; q$ é a capacidade de adsorção em um tempo (mmol.g $\left.{ }^{-1}\right) ; \quad t$ é o tempo (min); e $k_{1}$ é a constante cinética de primeira ordem $\left(\mathrm{min}^{-1}\right)$.

\subsubsection{Modelo de pseudossegunda ordem}

Esse modelo tem sido aplicado para análise cinética de quimissorção de soluções líquidas (Ho, 2006). Assume-se que um íon metálico é adsorvido em dois sítios de adsorção na superfície do adsorvente e é expresso pela Equação 4:

$\frac{q}{q_{e}}=\frac{k_{2} q_{e} t}{\left(1+K_{2} q_{e} t\right)}$

em que: $k_{2}$ é a constante cinética de segunda ordem $\left(\mathrm{g} \cdot \mathrm{mmol}^{-1} \cdot \mathrm{min}^{-1}\right)$.

\subsubsection{Modelo de difusão intrapartícula}

De acordo com a teoria proposta por Weber e Morris (1963), o modelo de difusão intrapartícula é expresso pela Equação 5:

$q=k_{i} t^{1 / 2}+c$

em que: $k_{i}$ é a constante de difusão intrapartícula $\left(\mathrm{mmol} \cdot \mathrm{g}^{-1} \cdot \mathrm{min}^{-0,5}\right)$ e $c$ é uma aproximação da espessura da camada limite.

\section{RESULTADOS E DISCUSSÃO}

\subsection{Especiação Química}

A Figura 1 apresenta a especiação química para todos os sais metálicos utilizados nesse estudo.

De acordo com a Figura 1(a) o íon $\mathrm{Cu}^{2+}$ é a espécie predominante até $\mathrm{pH} 5$, a partir do qual inicia a precipitação na forma de cristais de $\mathrm{CuO}$. $\mathrm{O}$ pH 5 também foi considerado o limite para o íon $\mathrm{Zn}^{2+}$, pois de acordo com a Figura 1(b), surge a forma iônica $\mathrm{ZnOH}^{+}$. A partir do $\mathrm{pH} 7$ é que a precipitação se inicia 
formando cristais de $\mathrm{ZnO}$. Para o íon $\mathrm{Cd}^{2+}$, o $\mathrm{pH}$ em que ocorre o surgimento de íons cristalinos é 8, como pode ser visto na Figura 1(c), com a formação de $\mathrm{Cd}(\mathrm{OH})_{2}$, abaixo desses valores só existem os íons $\mathrm{Cd}^{2+}$. Em relação ao íon $\mathrm{Pb}^{2+}$, o $\mathrm{pH}$ também teve que ser

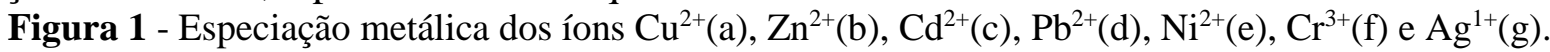

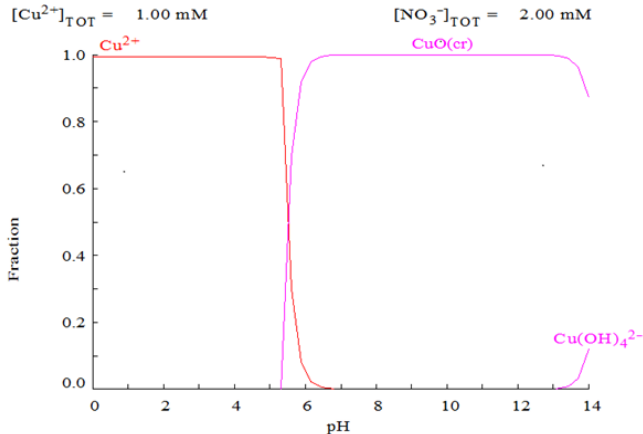

(a)

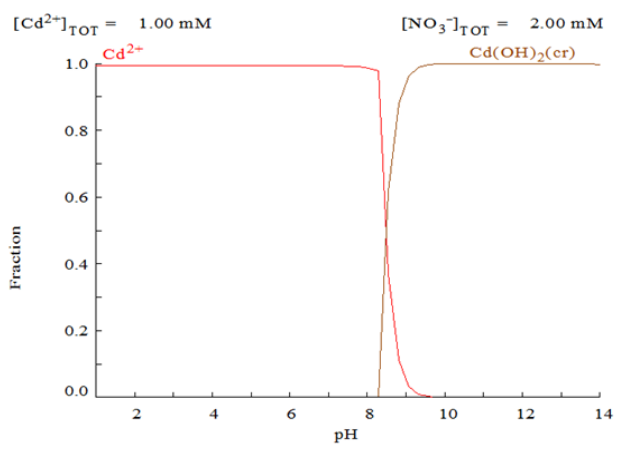

(c)

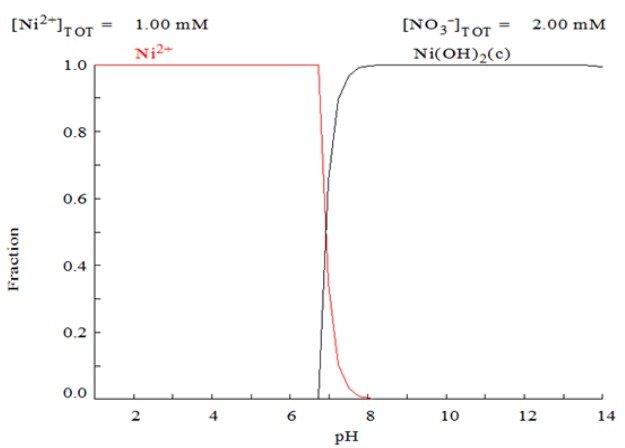

(e) mantido em 5, em função do aparecimento da espécie $\mathrm{Pb}(\mathrm{OH})_{2}$, como pode ser visto na Figura 1(d).

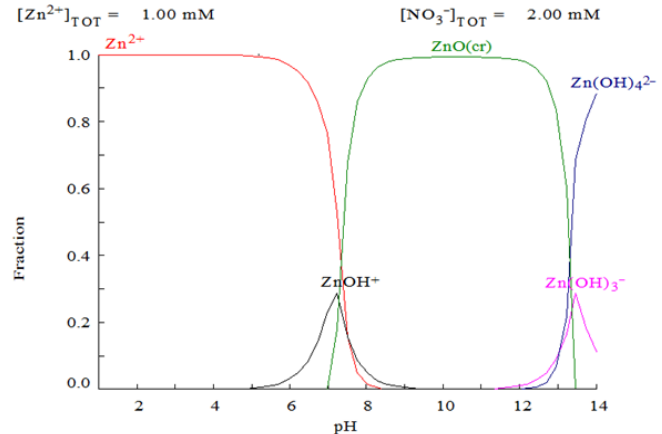

(b)

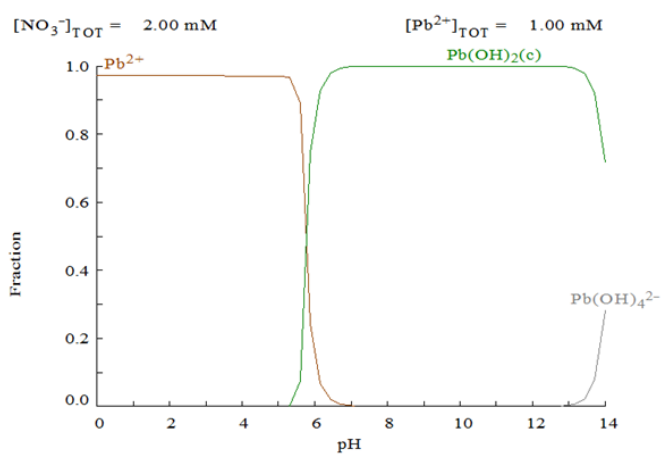

(d)

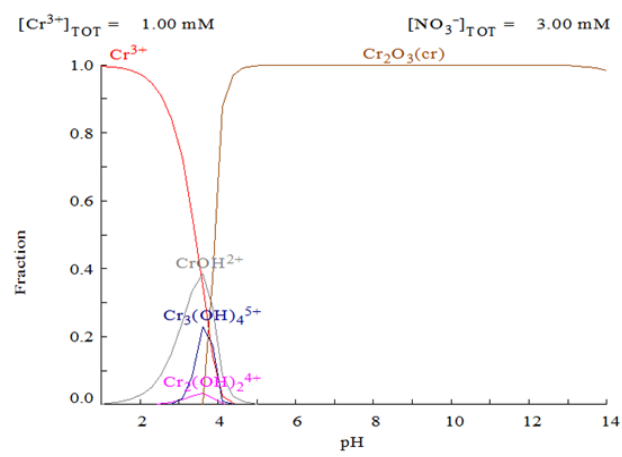

(f) 


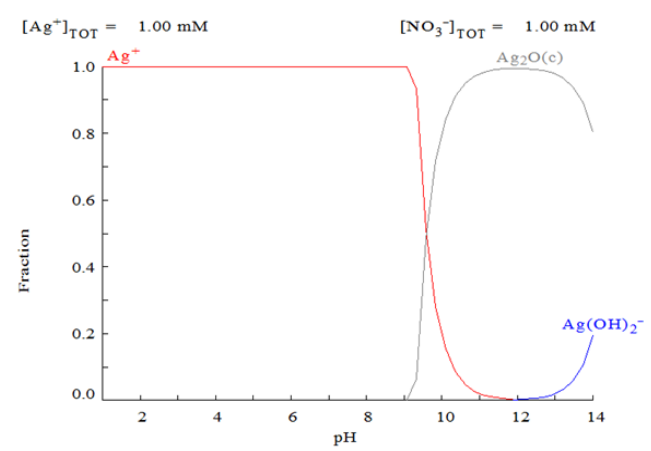

(g)

A partir da Figura 1(e), é possível observar que para $\mathrm{pH}$ acima de 6 o íon $\mathrm{Ni}^{2+}$ precipita na forma de hidróxido com a formação da espécie $\mathrm{Ni}(\mathrm{OH})_{2}$. Para o íon $\mathrm{Cr}^{3+}$, para um pH em torno de 3,5 começa a formação de cristais de $\mathrm{Cr}_{2} \mathrm{O}_{3}$; abaixo desse valor se encontram as formas iônicas $\mathrm{CrOH}^{2+}$, $\mathrm{Cr}_{3}(\mathrm{OH})_{4}{ }^{5+}$ e $\mathrm{Cr}_{2}(\mathrm{OH})_{2}{ }^{4+}$, como pode ser verificado na Figura 1(f). Na Figura 1(g), o íon $\mathrm{Ag}^{+}$inicia sua precipitação a partir de $\mathrm{pH}$ 9, com a formação da espécie $\mathrm{Ag}_{2} \mathrm{O}$, em $\mathrm{pH}$ inferior a esse valor só existe o íon $\mathrm{Ag}^{+}$.

Durante os ensaios de afinidade, os $\mathrm{pHs}$ foram mantidos sempre abaixo dos valores em que se inicia a precipitação, evitando que a formação de complexos ou precipitação de hidróxidos impeçam a adsorção dos íons metálicos nas partículas de sericina/alginato.

\subsection{Teste de Afinidade Metálica}

A Figura 2 apresenta a capacidade de remoção para todos os íons metálicos avaliados.

De acordo com a Figura 2 pode-se observar que as partículas de sericina/alginato apresentaram capacidade de remoção satisfatória para a maioria dos íons metálicos, possuindo maior afinidade com os íons $\mathrm{Cd}^{2+} \mathrm{e}$ $\mathrm{Cr}^{3+}$. A ordem de afinidade foi: $\mathrm{Cd}^{2+}>\mathrm{Cr}^{3+}>$ $\mathrm{Ni}^{2+}>\mathrm{Zn}^{2+}>\mathrm{Cu}^{2+}>\mathrm{Pb}^{2+}>\mathrm{Ag}^{+}$.
Figura 2 - Capacidade de adsorção para diferentes íons metálicos.

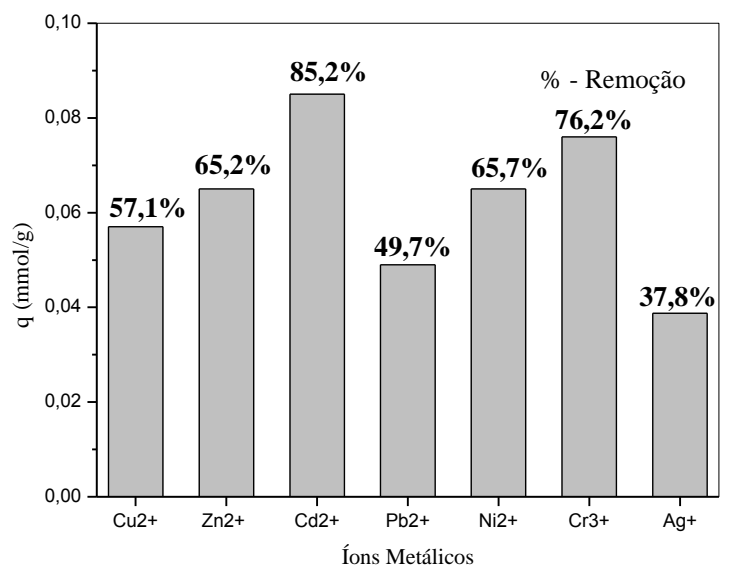

Diversos fatores, incluindo o tipo de adsorbato, condições experimentais e propriedade dos metais, como o raio iônico e a eletronegatividade, influenciam a sequência de afinidade. A teoria de bases e ácidos moles e duros também tem sido utilizada para justificar a ordem de afinidade dos metais, na qual ácidos fortes tendem a se associarem com bases fortes e ácidos fracos com bases fracas.

Os grupos amino e carboxila presentes na blenda estudada são classificados como bases duras, assim como o íon $\mathrm{Cr}^{3+}$ é classificado como ácido duro, o que explica sua alta afinidade com as partículas. Os íons $\mathrm{Ni}^{2+}, \mathrm{Cu}^{2+}, \mathrm{Zn}^{2+}$ e $\mathrm{Pb}^{2+}$ são classificados como ácidos intermediários, e o íon $\mathrm{Ag}^{+}$como ácido mole, o que justifica ter sido menos adsorvido 
apesar de possuir elevados eletronegatividade e raio iônico.

Essa teoria não se aplica ao íon de $\mathrm{Cd}^{2+}$, por ser um ácido mole e ter apresentado uma alta afinidade. No entanto o comportamento pode ser explicado pelo fato do cádmio apresentar valores relativamente elevados de eletronegativiade $(1,69)$, o que facilita a adsorção pelo bioadsorvente, e raio iônico $(0,970 \AA)$, uma vez que quanto maior o raio iônico, maior a capacidade adsortiva como demonstrado por TOBIN (1984). Além disso deve-se considerar a complexidade de sistemas biológicos e que vários fatores podem influenciar os mecanismos envolvidos na adsorção.

\subsection{Estudo Cinético}

As curvas cinétidas obtidas para diferentes concentrações iniciais, no caso, 0,5 ; 1 e $1,5 \mathrm{mmol} / \mathrm{L}$ de cádmio estão apresentadas na Figura 3.

Figura 3 - Curvas cinéticas para diferentes concentrações iniciais de cádmio.

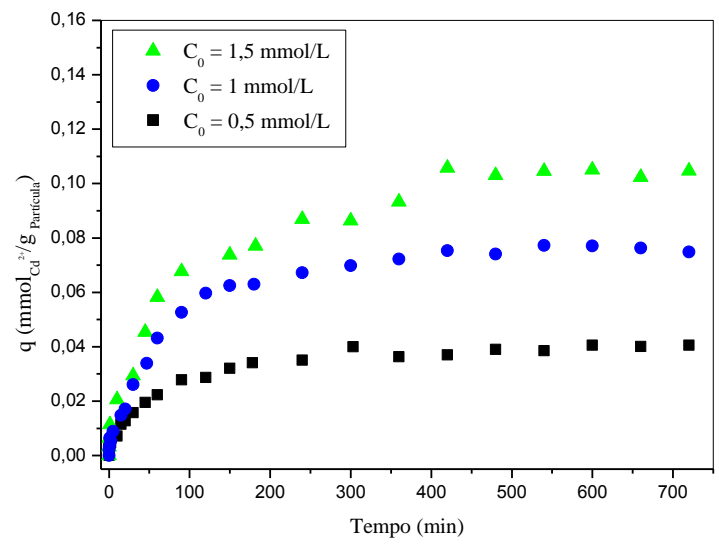

As curvas apresentam comportamento similar e a mesma forma contínua, o que sugere a possibilidade de adsorção em monocamada de $\mathrm{Cd}^{2+}$ na superfície do adsorvente. Verifica-se também que a adsorção é dependente da concentração inicial de cádmio na solução. Quanto maior a concentração, maior a capacidade de adsorção, o que pode ser explicado pelo maior gradiente de concentração, e consequentemente maior a força motriz de transferência de massa.

Pode ser notado na Figura 3 que o equilíbrio também depende da concentração inicial: ocorre em aproximadamente $300 \mathrm{~min}$ (0,5 mmol/L), $360 \mathrm{~min}(1 \mathrm{mmol} / \mathrm{L})$ e $480 \mathrm{~min}$ (1,5 mmol/L). A partir desses tempos, a taxa de adsorção tornou-se praticamente constante devido à saturação dos sítios de adsorção do adsorvente.

Os modelos cinéticos de pseudoprimeira ordem, pseudossegunda ordem e difusão intrapartícula foram ajustados aos dados experimentais a fim de se compreender a cinética de remoção de $\mathrm{Cd}^{2+}$ por partículas de sericina/alginato. Os resultados encontram-se nas Figuras 4 e 5.

Como mostrado na Figura 5, o gráfico de difusão intrapartícula exibe uma multilinearidade, indicando que a difusão intrapartícula não é a única etapa que controla a taxa de adsorção. As três fases estão envolvidas no processo de adsorção. A primeira seção linear representa a adsorção na superfície externa; a segunda fase descreve a adsorção gradual de $\mathrm{Cd}^{2+}$ nas partículas de sericina/alginato e na qual a difusão intrapartícula é o mecanismo limitante do processo de adsorção. A última etapa é o estado de equilíbrio dinâmico entre a adsorção e dessorção do íon metálico.

Os parâmetros obtidos por meio de ajuste não linear para as três concentrações iniciais de cádmio de acordo com os modelos propostos estão sumarizados na Tabela 1. Para o modelo de difusão intrapartícula foi realizado o ajuste linear nos pontos indicados pela reta tracejada. 
Figura 4 - Ajuste dos modelos de pseudoprimeira e pseudossegunda ordem para adsorção de $\mathrm{Cd}^{2+}$ em partículas de sericina/alginato.

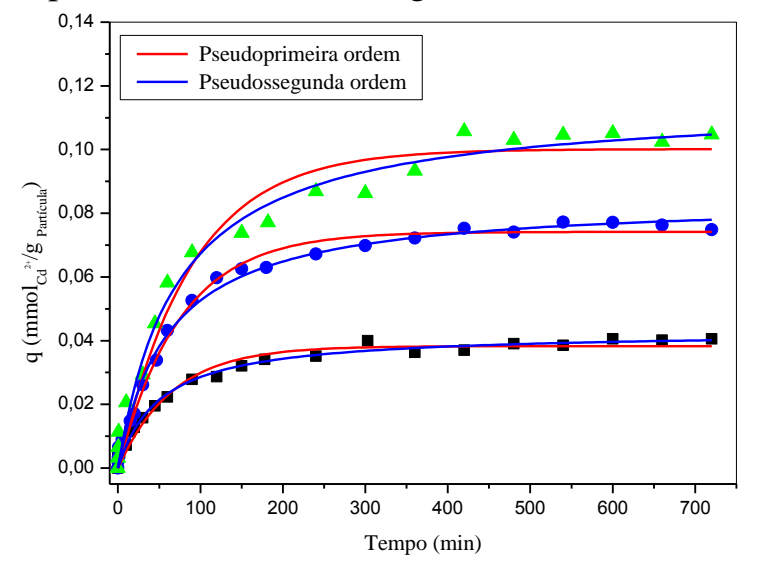

Figura 5 - Ajuste do modelo de difusão intrapartícula para adsorção de $\mathrm{Cd}^{2+}$ em partículas de sericina/alginato.

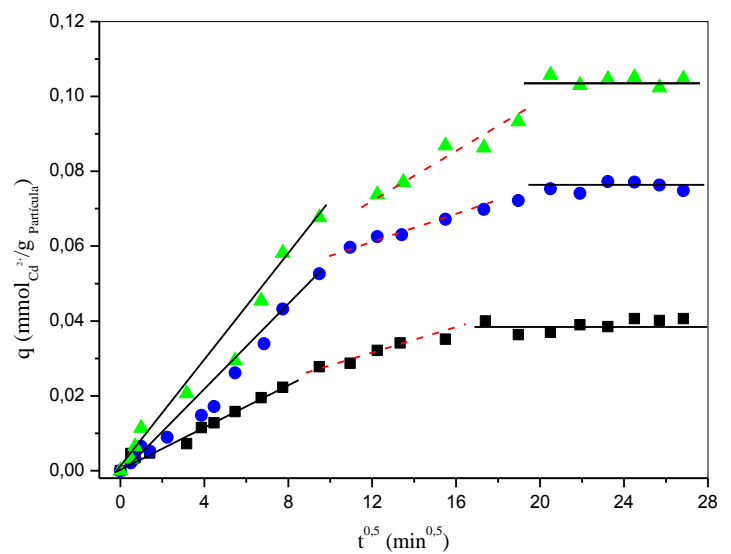

Tabela 1 - Parâmetros cinéticos para os modelos de pseudoprimeira ordem, pseudossegunda ordem e difusão intrapartícula para a bioadsorção de $\mathrm{Cd}^{2+}$ em partículas de sericina/alginato.

\begin{tabular}{|c|c|c|c|c|}
\hline \multirow{2}{*}{ Modelo } & \multirow{2}{*}{ Parâmetro } & \multicolumn{3}{|c|}{ Concentração Inicial (mmol.L $\left.{ }^{-1}\right)$} \\
\hline & & $\mathbf{0 , 5}$ & $\mathbf{1 , 0}$ & 1,5 \\
\hline & $\begin{array}{c}\text { qe experimental } \\
\left(\mathrm{mmol.g}^{-1}\right)\end{array}$ & 0,0404 & 0,0764 & 0,1048 \\
\hline \multirow{3}{*}{$\begin{array}{c}\text { Pseudoprimeira } \\
\text { ordem }\end{array}$} & $\mathrm{q}_{\mathrm{e}}\left(\mathrm{mmol} \cdot \mathrm{g}^{-1}\right)$ & 0,0383 & 0,0742 & 0,1001 \\
\hline & $\mathrm{k}_{1}\left(\min ^{-1}\right)$ & 0,0151 & 0,0133 & 0,0113 \\
\hline & $\mathrm{R}^{2}$ & 0,9723 & 0,9921 & 0,9695 \\
\hline \multirow{3}{*}{$\begin{array}{c}\text { Pseudossegunda } \\
\text { ordem }\end{array}$} & $\mathrm{q}_{\mathrm{e}}\left(\mathrm{mmol} \cdot \mathrm{g}^{-1}\right)$ & 0,0429 & 0,0845 & 0,1149 \\
\hline & $\mathrm{k}_{2}\left(\mathrm{~g} \cdot \mathrm{mmol}^{-1} \cdot \mathrm{min}^{-1}\right)$ & 0,4626 & 0,1945 & 0,1227 \\
\hline & $\mathrm{R}^{2}$ & 0,9857 & 0,9939 & 0,9846 \\
\hline \multirow{3}{*}{$\begin{array}{c}\text { Difusão } \\
\text { Intrapartícula }\end{array}$} & $\mathrm{k}_{\mathrm{i}}\left(\mathrm{mmol} \cdot \mathrm{g}^{-1} \cdot \mathrm{min}^{-0,5}\right)$ & 0,0013 & 0,0016 & 0,0028 \\
\hline & $\mathrm{c}\left(\mathrm{mmol} . \mathrm{g}^{-1}\right)$ & 0,0149 & 0,0403 & 0,0426 \\
\hline & $\mathrm{R}^{2}$ & 0,8929 & 0,9799 & 0,9045 \\
\hline
\end{tabular}

Da Tabela 1 verifica-se que os valores de $q_{e}$ calculados pelos modelos mostram uma boa concordância com os valores experimentais, o que indica que os modelos cinéticos de pseudoprimeira e pseudossegunda ordem descrevem adequadamente a remoção de $\mathrm{Cd}^{2+}$ utilizando as partículas de sericina/alginato em estudo. Verifica-se essa concordância na Figura 4, na qual pode-se visualizar que os dados experimentais são bem ajustados pelos modelos em estudo. Quando os dados experimentais foram ajustados com a cinética de pseudoprimeira ordem, os coeficientes de correlação foram um pouco mais baixos em relação ao de pseudossegunda ordem. Assim, pode concluir-se que a adsorção de $\mathrm{Cd}^{2+} \mathrm{em}$ partículas de sericina/alginato segue o modelo cinético de pseudossegunda ordem em que o passo limitante é assumido como sendo a 
adsorção química envolvendo a troca ou compartilhamento de elétrons entre $\mathrm{Cd}^{2+}$ e o adsorvente. Vázquez et al. (2009) também encontraram comportamento similar ao estudar adsorção de íons de cádmio em casca de castanha.

Verifica-se também que a taxa de pseudossegunda ordem (constante $\mathrm{k}_{2}$ ) diminui com o aumento na concentração inicial de $\mathrm{Cd}^{2+}$. Uma explicação para esta observação é que o número relativo de locais de adsorção vazios e facilmente acessíveis são reduzidos com o aumento das concentraçãoes iniciais. Como resultado, o processo leva mais tempo para atingir o equilíbrio e, portanto, a redução observada na taxa de adsorção.

Os valores de $\mathrm{k}_{\mathrm{i}}$ e c obtidos pelo modelo de difusão intrapartícula aumentaram com o aumento da concentração inicial, o que reflete o aumento da espessura da camada limite e a diminuição da possibilidade de transferência de massa externa, de modo que a difusão superficial torna-se uma etapa limitante deste processo.

\subsection{Avaliação de Área Superficial}

A Tabela 2 apresenta os resultados de Fisissorção de $\mathrm{N}_{2}$ obtidos para as partículas de sericina/alginato antes e após o processo de adsorção com íons cádmio.

Tabela 2 - Parâmetros obtidos por BET para as partículas de sericina/alginato.

\begin{tabular}{ccc}
\hline Propriedade & $\begin{array}{c}\text { Partícula de } \\
\text { Sericina/Alginato }\end{array}$ & $\begin{array}{c}\text { Partícula } \\
\text { contaminada } \\
\text { com íons de } \\
\text { cádmio }\end{array}$ \\
\hline $\begin{array}{c}\text { Área } \\
\text { Superficial } \\
\left(\mathrm{m}^{2} \cdot \mathrm{g}^{-1}\right)\end{array}$ & 3,702 & 3,243 \\
\hline $\begin{array}{c}\text { Volume de } \\
\text { microporos } \\
(\mathrm{cc} / \mathrm{g})\end{array}$ & 0,121 & 0,117 \\
\hline $\begin{array}{c}\text { Volume de } \\
\text { mesoporos } \\
(\mathrm{cc} / \mathrm{g})\end{array}$ & 1,193 & 1,014 \\
\hline
\end{tabular}

A área superficial determinada pelo método BET para a partícula de sericina/alginato foi de $3,702 \mathrm{~m}^{2} \cdot \mathrm{g}^{-1}$. Essa área é maior do que a encontrada por Chen et al. (2011) para o pó da sericina que foi de 1,5 $\mathrm{m}^{2} \cdot \mathrm{g}^{-1}$, verificando que ocorreu um aumento da área superficial do material formado pela sericina com o alginato, o que favorece sua aplicação como bioadsorvente.

Verificou-se que a área superficial e o volume de microporos e mesoporos diminuíram após o processo de adsorção, o que pode ser explicado pelo preenchimento dos microporos e das paredes dos mesoporos dutrante o processo de adsorção.

\section{CONCLUSÕES}

As partículas de sericina-alginato apresentaram boa capacidade de remoção para todos os íons metálicos, possuindo maior afinidade com os íons $\mathrm{Cd}^{2+} \mathrm{e} \mathrm{Cr}^{3+}$.

Os ensaios cinéticos de adsorção do $\mathrm{Cd}^{2+}$ para diferentes concentrações iniciais desse íon metálico indicaram que a adsorção é dependente deste parâmetro, mostrando que quanto maior a concentração maior a capacidade de adsorção no equilíbrio. Verificou-se também que a equação de pseudossegunda ordem forneceu os melhores ajustes aos dados experimentais. Em relação ao ajuste do modelo de difusão intrapartícula verificou-se uma multilinearidade, indicando que tanto a etapa de difusão no interior da partícula quanto a etapa de adsorção na superfície externa controlam o processo de transferência de massa.

Este material se mostrou eficiente e apresentou potencial de aplicação para a remoção de íons de cádmio de soluções aquosas.

\section{REFERÊNCIAS}


AGRAWAL, A; SAHU, K. K. Kinetic and isotherm studies of cadmium adsorption on manganese nodule residue. Journal of Hazardous Materials, v. 137, p. 915-924, 2006.

AZOUAOU, N.; SADAOUI, Z.; DJAAFRI, A.; MOKADDEM, $\mathrm{H}$. Adsorption of cadmium from aqueous solution onto untreated coffee grounds: Equilibrium, kinetics and thermodynamics. Journal of Hazardous Materials, v. 184, p. 126-134, 2010.

BOPARAI, H. K.; JOSEPH, M.; O'CARROLL, D. M. Kinetics and thermodynamics of cadmium ion removal by adsorption onto nano zerovalent iron particles. Journal of Hazardous Materials, v.186, p. 458-465, 2011.

CHEN, X.; LAM, K. F.; MAK, S. F.; YEUNG, K. L. Precious metal recovery by selective adsorption using biosorbents. Journal of Hazardous Materials, v. 186, p. 902-910, 2011.

HO, Y. S. Citation review of Lagergren kinetic rate equation on adsorption reactions. Scientometrics, v. 59, p. 171-177, 2004.

HO, Y. S. Review of second-order models for adsorption systems. Journal of Hazardous Materials, v. 136, p. 681-689, 2006.

NITÃ, I.; IORGULESCU, M.; SPIROIU, M. F.; GHIUREA, M.; PETCU, C.; CINTEZÃ, O. The adsorption of heavy metal ions on porous calcium alginate microparticles. Analele Universitatii din Bucuresti, Anul XVI, v. 1, p. 59-67, 2007.

PUIGDOMENECH, I. Hydra and Medusa Programs. Suécia: Royal Institute of Technology, 2004.
TOBIN, J. M.; COOPER, D. G.; NEUFELD, R. J. Uptake of metal ions by Rhizopus arrhizus biomass. Applied and Environmental Microbiology, v. 47, p. 821 824, 1984.

VÁZQUEZ, G.; FREIRE, M. S.; GONZÁLEZ-ALVAREZ, J.; ANTORRENA, G. Equilibrium and kinetic modelling of the adsorption of $\mathrm{Cd}^{2+}$ ions onto chestnut shell. Desalination, v. 249, p. 855-860, 2009.

WEBER, W. J.; MORRIS, J. C. Kinetics of adsorption on carbon from solution. Journal of the Sanitary Engineering Division, v. 89, p. 31-59, 1963.

ZHANG, Y. Q. Applications of natural silk protein sericina in biomaterials. Biothechnology Advances, v. 20, p. 91-100, 2002.

\section{AGRADECIMENTOS}

Os autores agradecem a FAPESP e ao $\mathrm{CNPq}$ pelo suporte financeiro para a realização da pesquisa e a BRATAC pelo fornecimento dos casulos. 